\title{
The Relationship Between Knowledge Management Capabilities and Product Innovation and Its Impact on Marketing Performance
}

\author{
Tundung Subali Patma \\ State Polytechnic of Malang, 9 Soekarno Hatta Street, 65141, Malang, Indonesia \\ Email: tundung2017@gmail.com \\ Ludfi Djajanto \\ State Polytechnic of Malang, 9 Soekarno Hatta Street, 65141, Malang, Indonesia \\ Email: ludfimlg@yahoo.com \\ Hanif Mauludin \\ Malangkuçeçwara School of Economics, Candi Kalasan Street, Malang, Indonesia \\ Email: hanifmauludin@gmail.com
}

\begin{abstract}
Competition in the market is unavoidable, especially in meeting the demands on cheaper cost and better quality. In the era of hypercompetitiveness, companies are encouraged to always create the uniqueness of products by making some innovations. Innovation has also attracted people to create more efficient and effective ways to reduce costs. Innovation is the source of competitive advantage for the company. Research has grown rapidly in demonstrating the benefits of interconnections between knowledge management, innovation, and company performance. The ability to use knowledge assets is effectively said to be one of the key guarantees of corporate success. Company performance will depend on the use of knowledgebased assets, innovation management, and integration practices. This study examines the relationship between knowledge management capability covering knowledge of infrastructure capability and knowledge process capability to product innovation and its impact on marketing performance. The sample of research is small and medium business in East Java Indonesia as many as 200 companies. This study used structural equation modeling approach based on partial least square (SEM-PLS). The results showed that there was a significant positive effect on knowledge infrastructure capability to knowledge process capability and product innovation. There is also a significant positive influence between knowledge process capability to product innovation. Our results also confirm that there is a very strong influence between product innovation on marketing performance.
\end{abstract}

Keywords: knowledge management capabilities, knowledge process capability, product innovation, knowledge process capability, marketing performance

Field of research: Marketing

\section{Introduction}

Studies show that there is a high correlation between product innovation and business results either in terms of modifications or new products with the strategic aim of capturing new markets 
or maintaining existing market share (Tidd, 2006). Krishnaswamy (2014) states that the main feature of innovation is the ability to work with customers in terms of research and development of the company to achieve product innovation that supports competitiveness, which leads to sustainable market growth. Related to marketing performance, some researchers such as Rahman et al. (2015); Verma and Jayasimha, (2014); Khurum et al. (2015) noted that in order to achieve market competitiveness as well as to maintain market satisfaction, a company must be able to increase innovation. Innovation in terms of product development can create uniqueness which distinguishes the company with its competitors. The purpose of product innovation is to develop through research and development activities and the use of technology to improve and create new products that bring products to market faster and more abundantly than competitors for superior marketing performance (Foret et al., 2014; Krishnaswamy, 2014; Khurum et al., 2015).

Innovation is the result of interaction and knowledge exchange involving resource diversity and interdependence (Landry, Amara, \& Lamari, 2002). The complexity of innovation emphasizes three important steps in the innovation process: 1) generating new knowledge for innovation, 2) gaining new products and processes, and 3) gaining economic benefits from new products launched in the market (Trott 2009). Seen from the business re-engineering perspective, a company must have the ability to innovate sustainably and improve through dramatic changes rather than just in partial changes. Especially today, the business world has experienced what is called "hypercompetitive" with the characteristics of relatively stable market demand but offering more offensive competitors. This hypercompetitive situation must be balanced with continuous innovation, speed in learning and responding to changes and consistently delivering quality products.

In the literature of strategic management, a knowledge-based outlook has shifted resource-based views (RBV). Knowledge is the most important resource in creating sustainable competitive advantage. Relevant to RBV, knowledge is a unique and valuable resource that is difficult to replicate and can be utilized to achieve sustainable competitive advantage (Barney 1991; Alavi and Leidner, 2001). Knowledge management encompasses all activities that utilize knowledge to achieve organizational goals in order to face environmental challenges and remain competitive in the marketplace. Along with the fame of knowledge management concept, it has attracted the interest of practitioners to know what knowledge management and how to apply it successfully in their business activities, it further has been treated as the foundation to build competitive advantage as well. Knowledge management is a need which has been grown as a result of changes in the environment, triggered by global competition, the speed of information, and the aging of knowledge as well as the dynamics of product and process innovation. The concept of knowledge management and its application will be a solution that can help companies to become more responsive to change and more innovative than their competitors. This means that knowledge management handles the interaction between the organization and the environment as well as the organizational ability to react and act. Organizations are entities that have the knowledge, whereas the basic function of a company is to integrate and use knowledge. 
Although not all knowledge management activities have a positive effect on business performance or to produce excellence competitiveness, many parameters and their interactions need to be considered for the successful implementation of knowledge management within an organization (Martina et al., 2007). Some of these parameters are related to how to recognize, create, transform, and distribute knowledge in corporate activities, as well as set up an effective and efficient way of working (Sangjae Lee et al., 2012). Some researchers emphasize the importance of infrastructure and knowledge management processes (Cha et al., 2008; Lee \& Steen, 2010). Research by Annette M. Mills et al. (2011) and Zack et al. (2009) showcase that knowledge management dimension consists of infrastructure knowledge (Alavi \& Leidner, 2001; Lee \& Choi, 2003) and knowledge process capability (Gold et al. , 2001). Both have an overall impact on organizational performance. Their results reveal that some indicators such as organizational structure, knowledge acquisition, knowledge application and knowledge protection are significantly related to organizational performance. However, indicators such as technology, organizational culture, and knowledge conversion have no significant impact on performance. These finding in fact still need to be reconfirmed through further research to test the consistency and generalization on other research objects.

This research uses the concept of knowledge management capability. It is defined as the ability to acquire, produce and combine the sources of knowledge in order to detect external threat opportunities, to explore the strengths and weaknesses of corporate resources, and to overcome some environmental dynamics through the condition between internal and external environments (Scherer, 2000). Knowledge-based dynamic ability consists of knowledge related to internal and external knowledge embedded in the company. Knowledge is the most valuable intangible asset and is not easily imitated by the competitors. It will trigger the birth of innovation within the company. Knowledge will change the old ways in doing business so that a company can be more competitive. Therefore, business managers use several ways to use knowledge in order to create superior product value (Quintas, 2002). However, how to efficiently control, apply, and develop knowledge to effectively generate and reuse knowledge is determined by the company's knowledge management capabilities. Previous researchers such as Davenport et al. (1998) and Soo et al. (2002) have investigated how companies effectively developed Knowledge Management capability to provide and share intangible assets to win the market competition. Knowledge management capabilities can also be the antecedent of innovation in an organization. Suli et al. (2011) found that there is a significant relationship between knowledge-based dynamic capabilities and innovation performance. In a dynamic market situation, companies must be skilled at utilizing internal and external resources to cope with the ever-changing environment. Knowledge Management capability emphasizes the constant search for a company to acquire, generate and merge/reconfigure knowledge base resources. Sources of knowledge gained major attention in this era of economics. Knowledge-based dynamic ability enables companies to continuously update their knowledge base, and thereby address the environmental change (Ambrosini \& Bowman, 2009).

Therefore, by considering those changes, knowledge management capabilities become an important pillar for achieving the company's long-term performance. In line with the above discussion, this paper aims to investigate the relationship between knowledge management capabilities and product innovation, also its impact on marketing performance. As a basis for 
fostering the theories and developing hypotheses, some of the earlier researchers have been adopted, such as Annette M. Mills, et al. (2011); Suli Zheng, et al. (2011); Chia-Nan Chiu and Huei-Huang Chen (2016).

\section{Theoretical background}

\subsection{Knowledge management capability as a source of competitive advantage}

In an organization, there are different levels of ability to apply and integrate resources to achieve corporate goals. Knowledge management has a function to foster the ability of the company to leverage the available knowledge through continuous learning in order to create new knowledge (Bose, 2003). Furthermore, Liu et al. (2004) assert that knowledge management's ability not only adheres to the ability to collect knowledge but also to protect knowledge and information to become a sustainable competitive advantage. Knowledge is the ultimate strategic resource for creating corporate value which the company seeks to develop to achieve its goals (Bhatt et al., 2005). It is therefore understandable that knowledge management capabilities have become a significant attribute of competitive advantage (Andrew, 2005). Lane et al. (2001) and Nooteboom (2000-journal 4) mention that Knowledge Management Capability (KMC) is measured by identifying the degree to which a company can acquire technology, marketing, managerial, manufacturing and other relevant knowledge from its partners. Knowledge generation capability has a similar structure as the knowledge acquisition capability which includes five items. These items measure how far a company can produce technology, marketing, managerial, manufacturing and other relevant knowledge. To see KMC more systematically and comprehensively, Gold et al. (2001) identify the capabilities of KM consisting of two dimensions: knowledge infrastructure and $\mathrm{KM}$ processes. Knowledge infrastructure includes technology, structure, and culture; whereas KM process involves an organization's ability to acquire, convert, apply, and protect knowledge. Effective knowledge infrastructure is essential in KM processes which aim to store, transform, and transfer knowledge. Fan et al. (2009) further incorporate the knowledge infrastructure, $\mathrm{KM}$ processes also propose seven attributes (i.e. technology, structure, culture, acquisition, conversion, deployment, and protection) to measure the organization's KM capabilities.

On the other hand, Aujirapongpan et al. (2010) describe the ability of KM of the enterprise is based on the perspectives of resource-based and knowledge. Resource-based capabilities refer to several different resources to investigate KM capabilities in determining different resources. These resources may result in different KM capabilities and also affect the capability of KM infrastructure, including technology, organizational structure, and culture. Furthermore, the perspective of knowledge-based capabilities primarily emphasizes on intangible assets, KM processes, and the management of various types of knowledge. Aspects that affect the capability of KM are based on knowledge-based perspectives comprising skills, learning, and information skills. This study defines the ability of KM is the ability of the company to utilize the existing knowledge to create and protect new knowledge. Furthermore, the company must combine skills and personal knowledge, physical and technical power, structure and culture to stimulate the dynamics of ongoing knowledge (Prieto and Easterby-Smith, 2006). 


\subsection{Relationship among knowledge management capabilities, Product Innovation, and Marketing performance}

As discussed earlier, the foundation of knowledge consists technology, structure, and culture; whereas KM process includes the organization's ability to acquire knowledge. The combination, implementation, and protection is an important antecedent of innovation. Among many, the functions of $\mathrm{KMC}$ is to contribute more to the activity of creating innovation and performance. Transforming internal and external knowledge into new knowledge through new ways of configuration in accordance with the market dynamics. KMC provides a knowledge base to be effectively acquired and generated in order to expand the knowledge of the company which will generate innovation. The speed of innovation will depend on knowledge infrastructure and process knowledge (Gold et al. (2001); Prieto \& Easterby-Smith, 2006; Fan et al., 2009; Aujirapongpan et al. 2010). Previous researchers have shown a link between knowledge and innovation management (Hidalgo \& Albors, 2008). Such innovation management involves the application of knowledge to the work of knowledge. Knowledge-based management infrastructure is done by limiting bureaucracy but the character is dealing more with flexible structures which encourage creativity to deliver new innovations. Chesbrough (2003) considers the importance of accessing outside knowledge and shares the internal knowledge to others as a good strategy to support innovation. The process of developing new products as a dynamic situation in which complex interactions occur. This requires integration to build new capabilities that meet the market demand (Marsh and Stock, 2003). Gardner et al. (2012) examine how teams can develop knowledge integration capabilities to dynamically integrate organizational resources into higher performance. This can be done by distinguishing between three resources-relational, experiential, and structural tools which differently affect the ability of team knowledge integration. Miles et al. (2009) suggest the need to improve knowledge by sharing and collaborating in entrepreneurial actions to improve performance. In this paper, the emphasis on corporate performance is more on marketing performance. Marketing is one of the key functions within a business organization. The marketing department's duty is to provide sufficient information for the production department to create products in keeping with the market demand. One of the goals of the marketing department is to achieve sales. In selling activities, the marketing department will be faced with two conditions: facing consumers who are sensitive to price and those who are sensitive to quality.

In order to address both conditions, all units in an organization must have the same information available at the same time. Delays in information received from each work can weaken the coordination. Therefore, KMC occupies a very strategic position. KMC required in the organizational context must learn to find new ways and thinking to support innovation. In fact, innovation is an important factor for the achievement of marketing performance. The continuous intake of innovation is a source of sustainable competitive advantage. Innovation is needed not only to maintain product life cycle but also to create life cycle that will follow the market demands. 
Based on the above explanation, this study proposes theoretical framework and hypothesis as follows (see Figure 1).

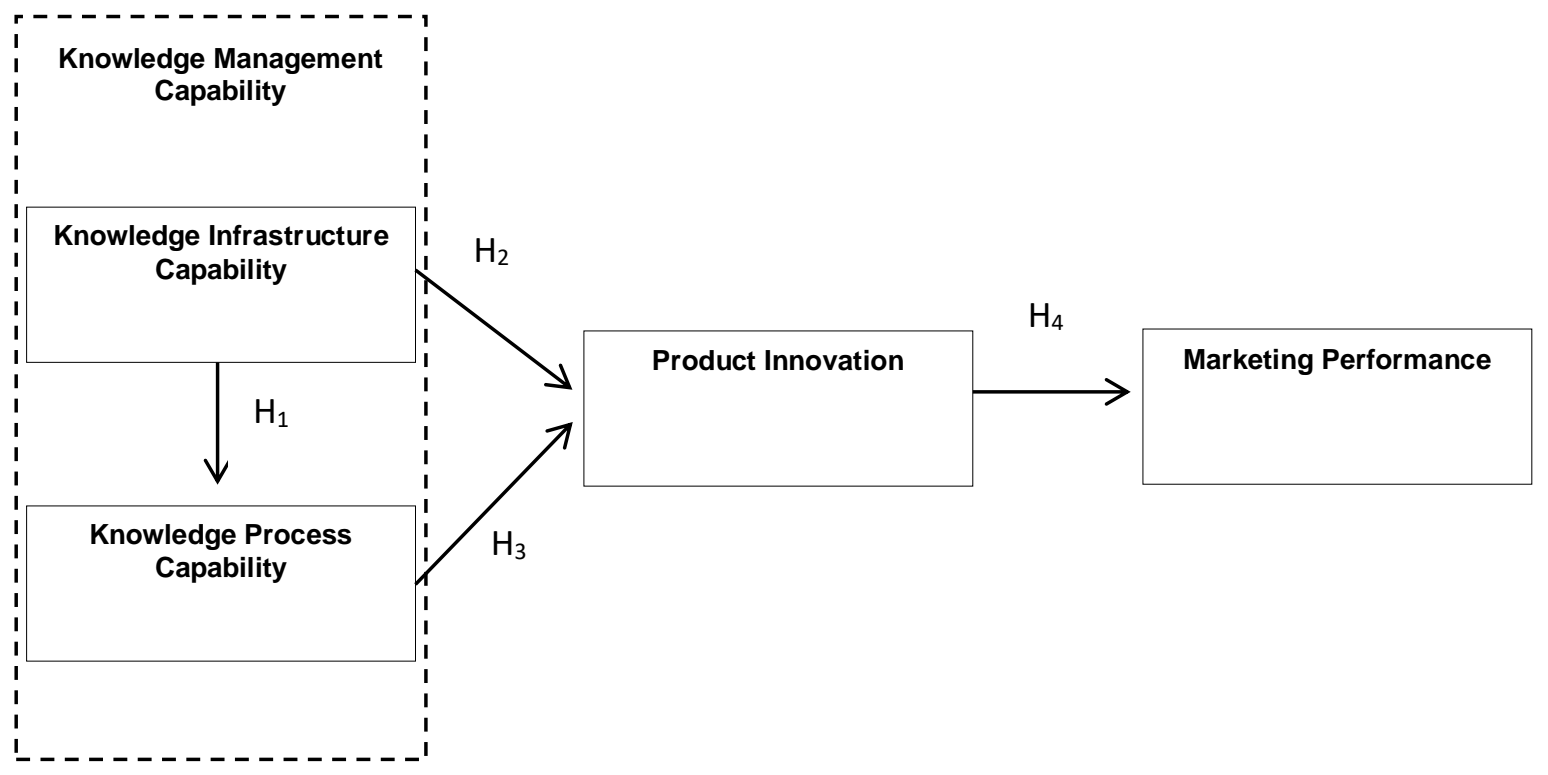

\section{Figure 1. Theoretical Framework}

Based on the theoretical framework, the hypothesis statement which is tested as follows:

$\mathrm{H}_{1}$ : Knowledge Infrastructure Capability affects Knowledge Process Capability

$\mathrm{H}_{2}$ : Knowledge Infrastructure Capability affects Product Innovation

$\mathrm{H}_{3}$ : Knowledge Process Capability affects Product Innovation

$\mathrm{H}_{4}$ : Product Innovation affects Marketing Performance

\section{Methodology}

\subsection{Samples and Measurements}

The purpose of this research is to find out the effect of KMC dimensions (including Knowledge Infrastructure Capability and Knowledge Process Capability) towards product innovation. Furthermore, this research aims to determine the effect of product innovation on marketing performance. This study involves small and medium enterprises with the main categories of companies in the field of the service industry, technology, and manufacturing. The sample of research is small and medium business in East Java Indonesia as many as 200 companies. The sampling method used in this research is purposive sampling with the criteria that the financial performance was in healthy condition during last three years, and the companies have some various products innovation to reach the wide market. The questionnaire items in the questionnaire can be seen in Table 1. The five points of the Likert scale, ranging from 1 (Very unfavorable) to 5 (Excellent) is used to measure research variables. 


\subsection{Questionnaires and Data Analysis}

The main tool of data collectors is the questionnaires in which the filling is represented by the owner or senior manager. Questionnaires were distributed directly in the forum of small medium enterprises in East Jawa, Indonesia. Totally, there are 200 questionnaires collected. The hypothesis testing was using partial least square with SMARTPLS Ver. 2.0 which includes outer measurement model and inner model measurement.

\subsection{Validity and reliability}

To find out whether the research instrument in the questionnaire meets the validity and reliability, we used partial least square by looking at the value of load factor and the AVE value (Average Varian Extracted) and the reliability test that we see was from the Cronbach alpha value. In Table 1, the value of loading each indicator has exceeded the minimum limit of 0.7. Thus, the research indicator has good validity. The value of Cronbach alpha in each construct reaches 0.7 indicating that the construct has a good degree of reliability. In addition, the AVE value also has a loading value above 0.5 which indicates that the latent construct explains at least $50 \%$ of the indicator variant.

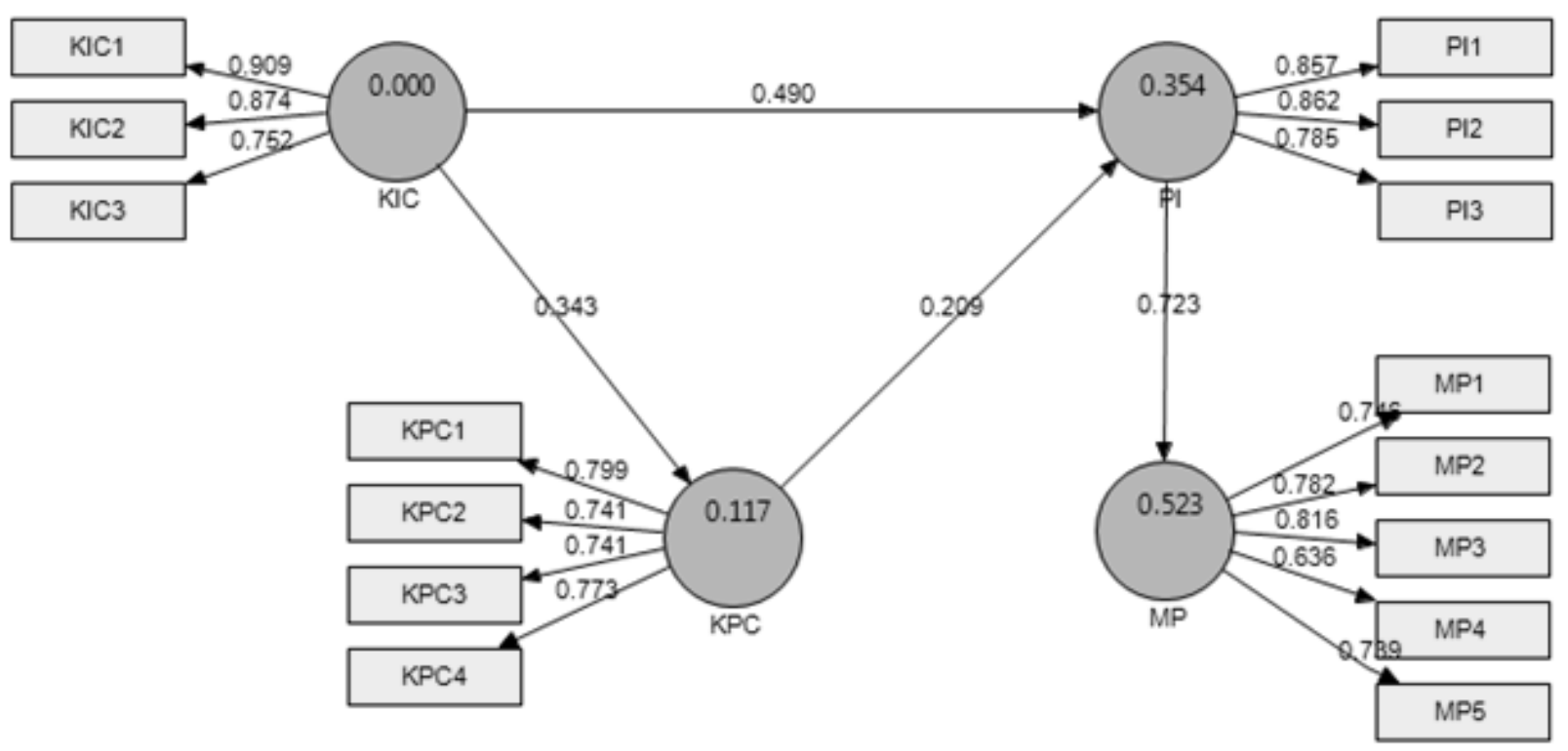

Figure 2. The results of measurement (outer model)

Tabel 1. Indicator of Loading, Average Varian Extracted and Cronbach's Alpha

\begin{tabular}{|c|c|c|c|c|}
\hline Constructs & Indicators & $\begin{array}{l}\text { Loadin } \\
\text { g factor }\end{array}$ & $\begin{array}{c}\mathrm{AV} \\
\mathrm{E}\end{array}$ & $\begin{array}{c}\text { Cronbach' } \\
\text { s Alpha }\end{array}$ \\
\hline \multirow{3}{*}{$\begin{array}{l}\text { Knowledge Infrastructure } \\
\text { Capability (KIC) } \\
\text { (Lee and Choi.2003) }\end{array}$} & Organizational structure (KIC1) & 0.90 & \multirow[t]{3}{*}{0.71} & \multirow[t]{3}{*}{0.79} \\
\hline & Organizational culture (KIC2) & 0.87 & & \\
\hline & Technology Infrastructure(KIC3) & 0.75 & & \\
\hline
\end{tabular}




\begin{tabular}{|c|c|c|c|c|}
\hline \multirow{4}{*}{$\begin{array}{l}\text { Knowledge Process Capability } \\
\text { (KPC) } \\
\text { (Gold et al. 2001) }\end{array}$} & Knowledge acquisition (KPC1) & 0.79 & \multirow[t]{4}{*}{0.58} & \multirow[t]{4}{*}{0.78} \\
\hline & Knowledge conversion (KPC2) & 0.74 & & \\
\hline & Knowledge application (KPC3) & 0.74 & & \\
\hline & Knowledge protection (KPC4) & 0.77 & & \\
\hline \multirow{3}{*}{$\begin{array}{l}\text { Product Innovation (PI) } \\
\text { (De Luca and Atuahene- } \\
\text { Gima. 2007) }\end{array}$} & Introduced new products (PI1) & 0.85 & \multirow[t]{3}{*}{0.55} & \multirow[t]{3}{*}{0.79} \\
\hline & Innovation improvement (PI2) & 0.86 & & \\
\hline & Innovations breakthrough (PI3) & 0.78 & & \\
\hline \multirow{5}{*}{$\begin{array}{l}\text { Marketing Performance } \\
\text { (MP) } \\
\text { (Vijande. Leticia Santos. } \\
\text { 2012) }\end{array}$} & Added value provided to customer (MP1) & 0.74 & \multirow[t]{5}{*}{0.69} & \multirow[t]{5}{*}{0.78} \\
\hline & Customer satisfaction (MP2) & 0.78 & & \\
\hline & Improved customers perceived image of the firm (MP3) & 0.81 & & \\
\hline & Reduction in the number of customer complaints (MP4) & 0.63 & & \\
\hline & Retained most-valued customers (MP5) & 0.73 & & \\
\hline
\end{tabular}

\section{Results and Analysis}

\subsection{Descriptive analysis}

The number of companies as the sample of research is 200 small and medium scale companies operating in East Java Indonesia. They are from the service industry, technology, and manufacturing. Table 2 below shows the sample description of the research sample.

Table 2 Respondents' Demographic Characteristics

\begin{tabular}{|l|l|l|}
\hline Variable & \multicolumn{1}{|c|}{ Type } & \multicolumn{1}{c|}{ Total } \\
\hline \multirow{3}{*}{ Types of business } & Service & 13 \\
\cline { 2 - 3 } & Technology & 16 \\
\cline { 2 - 3 } & manufacturer & 171 \\
\hline Length of operation & $<10$ years & 123 \\
\hline & $10-25$ years & 60 \\
\hline Market size & $>25$ years & 17 \\
\hline & Local - Regional & 158 \\
\hline Product variation & Export & 42 \\
\hline & $<5$ types of product & 36 \\
\hline & $5-10$ types of product & 142 \\
\hline & $>10$ types of product & 22 \\
\hline
\end{tabular}

Table 2 indicates that the sample of research is dominated by manufacturing companies. In general, especially in East Java, the growth of manufacturing industry sector is quite rapid along with a very strategic location. This is also shown from the dominant corporate age demographic which is still under the age of 10 years as an indication of the number of new companies operating. In terms of marketing coverage, it appears that is still dominated by the local and regional market. The ability to export still becomes a challenge in the industry in East Java. Some government policies were rolled out in order to increase exports. The ability to produce a varied product is quite encouraging where as many as 142 companies reported having a product variation between 5-10 types. This potential is quite good to develop. In fact, our research chose the size of marketing performance as a company performance proxy. The reason is that marketing is a classic problem that is dominantly faced by small medium enterprises (SMEs) rather than production and financial problems. In terms of funding, the government of Indonesia has been 
very aggressive to involve technology to SME. Special marketing is still a serious problem as foreign product strikes as a consequence of the implementation of Asian Economic Community (MEA). Thus, our research theme is very strategic because it examines the relationship between knowledge management to product innovation and its impact on marketing performance.

\subsection{Analysis of SEM PLS}

The result of partial least square analysis to test the influence of Knowledge Infrastructure Capability towards Knowledge Process Capability and Product Innovation and the influence of product innovation on marketing performance is shown in Figure 2 and Table 3.

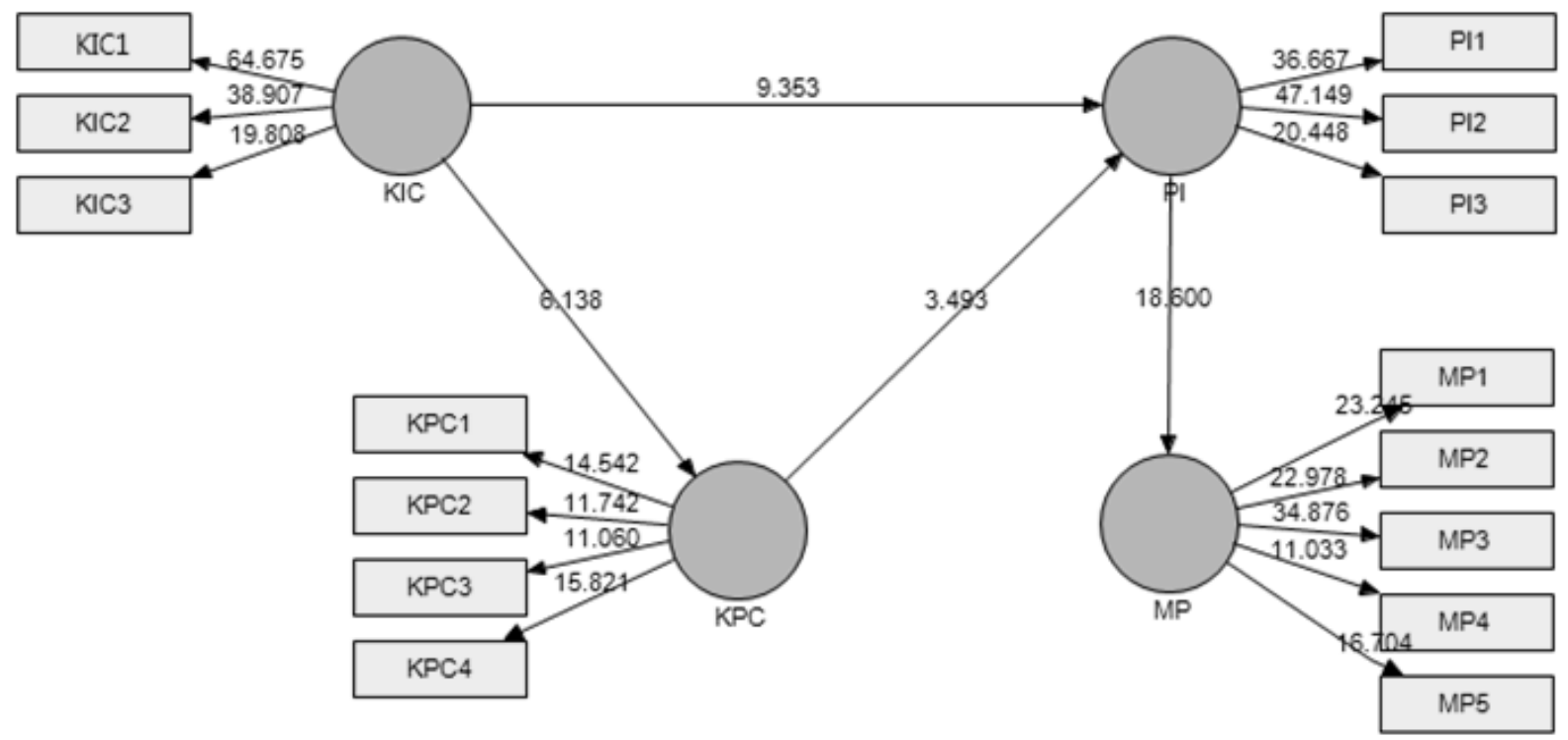

Figure 2. The results of the dimensional level (inner model)

Table 3. Path Coefficients (Mean, STDEV, T-Values)

\begin{tabular}{|l|c|c|c||c|c|c|}
\hline & $\begin{array}{c}\text { Original } \\
\text { Sample (O) }\end{array}$ & $\begin{array}{c}\text { Sample } \\
\text { Mean (M) }\end{array}$ & $\begin{array}{c}\text { Standard } \\
\text { Deviation } \\
\text { (STDEV) }\end{array}$ & $\begin{array}{c}\text { Standard } \\
\text { Error } \\
(\text { STERR) }\end{array}$ & $\begin{array}{c}\text { T Statistics } \\
(\mid \text { O/STERR })\end{array}$ & Sig P \\
\hline KIC -> KPC & 0.342500 & 0.351525 & 0.055797 & 0.055797 & 6.138287 & 0.00 \\
\hline KIC -> PI & 0.490423 & 0.493896 & 0.052433 & 0.052433 & 9.353327 & 0.00 \\
\hline KPC -> PI & 0.208520 & 0.213274 & 0.059689 & 0.059689 & 3.493449 & 0.00 \\
\hline \hline PI -> MP & 0.723352 & 0.726400 & 0.038891 & 0.038891 & 18.599525 & 0.00 \\
\hline
\end{tabular}

The result of the partial least squares analysis in Table 3 reveals that knowledge of infrastructure capability has a significant influence on knowledge process capability and product innovation. Knowledge process capability has a significant influence on product innovation. Further, product innovation has a significant influence on marketing performance. However, variable knowledge process capability and product innovation proved as an intervening variable. The study showed 
the positive coefficient and significant at 0.05. It also shows that the variables in the model which we tested such as infrastructure capabilities, we found that knowledge process innovation affects product capabilities and positively to marketing performance. The results of Path analysis as shown in Figure 2 demonstrates that the coefficient value path for the relationship between product innovation and marketing performance is very large as much as 0.7 . This shows that product innovation has a large contribution to marketing performance. On the other hand, the antecedent of the most dominant influence on product innovation capability is the knowledge infrastructure with a coefficient of 0.490 while the coefficient for the knowledge process capability by 0,208 .

\section{Discussion and implication}

The results of the study indicate that knowledge of infrastructure capability is associated with knowledge process capability and product innovation capability performed by the company either directly or indirectly. In building Knowledge infrastructure capability, it requires the support of fundamental aspects such as organizational structure (KIC1), organizational culture (KIC2), and technology Infrastructure (KIC3). The result of the measurement model test shows that the organization structure indicator has the largest loading factor of 0.90 , which is the most dominant indicator of knowledge infrastructure capability. The acquisition of knowledge requires the support of dynamic organizational structure rather than bureaucratic. A corporate culture which is open to new phenomenon will cause the flow of information can be easily accepted and responded by employees within the company.

The organizational structure will determine the rules, responsibilities, and authority related to the functions of supervision, coordination, and information spread in the company. Seen in the context of knowledge management, structure organization emphasizes in the decentralization of authority. This starts from participatory decision making where the upper management invites subordinates to provide suggestions, information, and ideas in the decision-making process. This form of the structure will open up space for information from multiple sources and ultimately help companies acquire knowledge more effectively. Furthermore, companies that have an organic structure usually spread information more freely. This opens the opportunity of the twoway communication system. Top management provides instructions and guidance to subordinates, similarly, the subordinates provide information to managers about the achievements and problems that they face. Such two-way communication is very effective in solving problems and therefore has an impact on performance. The findings support the results of Lee and Choi's research (2003). Our study also found that the two dimensions of knowledge management capability (including knowledge of infrastructure capability and knowledge process capability) have a significant positive effect on product innovation. Knowledge management capability is currently considered by many scientists as a global competing capital. Product innovation is one of the main competition requirements with the current era of knowledge management.

Literature in management has underlined that knowledge has been a source of sustainable competitive advantage in an unstable business situation where product innovation is an ongoing 
process that needs new knowledge and new approaches (Corso, M., Martini, A., Paolucci, E. \& Pellegrini, L. 2001). Knowledge management has a positive effect on the innovative performance of a company, especially knowledge that comes from external sources. New knowledge will bring new ideas and create creativity to support new products (Czarnitzki, Dirk \& Wastyn, Annelies, 2009). Our research also found that among the three product of innovation indicators (consisting of Introduced New Products (PI1), Innovation Improvement (PI2), and Innovation Improvement (PI3)) had the greatest loading i.e. Innovation Improvement (PI2) with the loading value of 0.86 . These findings reinforce the idea that in the context of innovation the main factor is an improvement. Basically, improvement is a part of the approach to make the work more effective and efficient. Some respondents even have a slogan company "our product is an improvement". We assume that the slogan as very motivating and awakening that must be considered by the company.

Overall, our research emphasizes that when a company succeeds in making knowledge acquisition, it will improve the product innovation. If the company succeeds in supplying some creative ideas for the development and enrichment of new products then it will create the better marketing performance. Therefore, a company must become a learning organization that will implement knowledge management in an effective way. Consequently, companies should have more organic organizational structures- decentralized than mechanistic-centralized. Our study notes that the majority of sample companies tend to have organic structures rather than mechanistic. We also found in the research sample that companies that are responsive and have documented external information are found to perform their information much better. They can quickly respond to changes related to consumer prices and preferences so that they always anticipate the market dynamics.

\section{Conclusion}

Indonesia with all its potentials will always be interesting as a foreign product destination. Indonesian consumer market is so attractive which triggers the competition in local, regional, and even global. Such situations should awaken the local players to be ready with a variety of imported product pressures such as cheaper products with better quality. The challenge for local players is innovation and efficiency. In fact, consumers are always sensitive to price and quality, therefore knowledge management is not just the needs of large companies. Small medium enterprises (SME) also need to make knowledge management as a part of corporate strategy. The literature review in this study examines the extent of knowledge management as an antecedent product innovation and its impact on company performance. We found that the knowledge management dimension comprises knowledge infrastructure capability and knowledge process capability which both have an impact on product innovation. Although both of them generate different results, knowledge infrastructure capability has a greater influence on product innovation. Moreover, product innovation has a positive and significant impact on marketing performance. Some of the indicators of this study which are vital to be a record for the company is 'organizational structure and organizational culture'. The results of our study undicate that the majority of SMEs have an organic structure rather than bureaucratic structure. 
This can be because the company is a family company. Family culture and mutual cooperation which have developed in Indonesia also influence the application of organic organizational structure. This family culture causes employees to become freer to communicate. Indirectly, it will support the exchange of existing knowledge. Thus, the acquisition process both internal and external is possible. Generally, our results also support some previous research such as Rahman et al. (2015); Verma and Jayasimha, (2014); Khurum et al., (2015); Gold et al. (2001); Prieto and Easterby-Smith (2006); Fan et al. (2009); Aujirapongpan et al. (2010); Hidalgo and Albors, (2008) who believe that knowledge management and innovation are interrelated to the company's performance. The limitations of the research indicate that the researchers did not provide a more in-depth study on research indicators. During the research process especially in the interview session with some business actors, we finally realized that it is necessary to elaborate more in-depth research indicators, for example, the indicator of corporate culture. Assessing corporate culture will ultimately explain sub-cultures so that information related to organizational culture will be widely identifiable. Therefore, further research is suggested to study operationalize research variables more detail through the development of the indicator.

\section{Reference}

Alavi, M. and Leidner, D.E. 2001. "Review: knowledge management and knowledge management systems: conceptual foundations and research issues', MIS Quarterly, Vol. 25 No. 1, pp. 107-36.

Ambrosini, V. and Bowman, C. 2009. "What are dynamic capabilities and are they a useful construct in strategic management?', International Journal of Management Reviews, Vol. 11 No. 1, pp. 29-49.

Andrew, L.S.G. 2005. "Harnessing knowledge for innovation: an integrated management framework", Journal of Knowledge Management, Vol. 9 No. 4, pp. 6-18.

Annette M. Mills and Trevor A. Smith. 2011. Knowledge management and organizational performance: a decomposed view, Journal of Knowledge, Vol. 15 No. 1, pp. 156-171.

Aujirapongpan, S., Vadhanasindhu, P., Chandrachai, A. and Cooparat P. 2010. "Indicators of knowledge management capability for KM effectiveness", The Journal of Information and Knowledge Management Systems, Vol. 40 No. 2, pp. 183-203.

Bhatt, G., Gupta, J.N.D. and Kitchens, F. 2005. "An exploratory study of groupware use in the knowledge management process", Journal of Enterprise Information Management, Vol. 18 No 1/2, pp. 28-46.

Cha, H.S., Pingry, D.E. and Thatcher, M.E. 2008. "Managing the knowledge supply chain: an organizational learning model of information technology offshore outsourcing', MIS Quarterly, Vol. 32 No. 2, pp. 281-306.

Chesbrough, H.W. 2003. Open Innovation: The New Imperative for Creating and Profiting from Technology, Harvard Business Press, Boston, MA.

Chia-Nan Chiu and Huei-Huang Chen. 2016. The study of knowledge management capability and organizational effectiveness in Taiwanese public utility: the mediator role of organizational commitment, SpringerPlus Vol. 5.

Corso, M., Martini, A., Paolucci, E. and Pellegrini, L. 2001. "Knowledge management in product innovation: an interpretative review". International Journal of Management Reviews, 3: 341-352. doi:10.1111/1468-2370.00072. 
Czarnitzki, Dirk and Wastyn, Annelies. 2009. Does Professional Knowledge Management Improve Innovation Performance at the Firm Level? ZEW - Centre for European Economic Research Discussion Paper No. 09-067. Available at SSRN: https://ssrn.com/abstract=1504068 or http://dx.doi.org/10.2139/ssrn.1504068.

Davenport, T.H., De Long, D. and Beers, M.C. 1998. "Successful knowledge management projects", Sloan Management Review, Vol. 39 No. 2, pp. 43-57.

De Luca, L. M., \& Atuahene-Gima, K. 2007. "Market knowledge dimensions and crossfunctional collaboration: Examining the different routes to product innovation performance". Journal of Marketing, 71(1), 95-112.

Fan, Z.P., Feng, Bo., Sun, Y.H. and Ou,W. 2009. "Evaluating knowledge management capability of organizations: a fuzzy linguistic method", Expert Systems with Applications, Vol. 36 No. 2, pp. 3346-3354.

Foret, Jerad A., Steen, John and Verreyrute. Martie-Louise. 2014. "How environmental regulations affect innovation in the Australian oil and gas industry: going beyond the Porter Hypothesis". Journal of Cleaner Production, 84, 204-213.

Gardner, H.K., Gino, F. and Staats, B.R. 2012. "Dynamically integrating knowledge in teams: transforming resources into performance", Academy of Management Journal, Vol. 55 No. 4, pp. 988-1022.

Gold, A.H., Malhotra, A. and Segars, A.H. 2001. "Knowledge management: an organizational capabilities perspective', Journal of Management Information Systems, Vol. 18 No. 1, pp. 185-214.

Hidalgo, A. and Albors, J. 2008. "Innovation management techniques and tools: a review from theory and practice', R\&D Management, Vol. 38 No. 2, pp. 113-127.

Khurum, Mahvish, Fricker, Samuel and Gorschek, Tony. 2015. The contextual nature of innovation- An empirical investigation of three software-intensive products. Infonnalion and Software Technology, 57, 595-613.

Landry, R., N. Amara and M. Lamari (2002), "Does Social Capital Determine Innovation? To What Extent?", Technological Forecasting and Social Change, 69 (7): 681-701.

Lane, P.J., Salk, J.E. and Lyles, M.A. 2001. “Absorptive capacity, learning, and performance in international joint ventures', Strategic Management Journal, Vol. 22 No. 12, pp. 1139-61.

Lee, D. and Steen, E.V.D. 2010. "Managing know-how', Management Science, Vol. 56 No. 2, pp. 270-85.

Lee, H. and Choi, B. 2003. "Knowledge management enablers, processes, and organizational performance: an integrative view and empirical examination', Journal of Management Information Systems, Vol. 20 No. 1, pp. 179-228.

Marsh, S.J. and Stock, G.N. (2003), "Building dynamic capabilities in new product development through intertemporal integration', Journal of Product Innovation Management, Vol. 20 No. 2, pp. 136-148.

Martina E. Greiner, Tilo Bohmann and Helmut Krcmar. 2007. "A strategy for knowledge management", Journal of Knowledge, Vol. 11 No. 6, pp. 3-15.

Miles, R.E., Miles, G., Snow, C.C., Blomqvist, K. and Rocha, H. 2009. "The I-form organization', California Management Review, Vol. 51 No. 4, pp. 61-76.

Nooteboom, B. 2000. Learning and Innovation in Organizations and Economies, Oxford University Press, New York, NY. 
Prieto, I.M. and Easterby-Smith, M. 2006. "Dynamic capabilities and the role of organizational knowledge: an exploration", European Journal of Information Systems, Vol. 15 No. 5, pp. 500-510.

Rahman, Mohd Nizam Ab, Doroodian, Mahmood, Kamarulzaman, Yusniza and Muhamad. Norhamidi. 2015. Designing and Validating a Model for Measuring Sustainability of Overall Innovation Capability of Small and Medium-Sized Enterprises. Sustainability 2015, 7, 537-562; doi:10.3390/su7010537.

Sangjae Lee, Byung Gon Kim and Hoyal Kim. 2012. An integrated view of knowledge management for performance, JOURNAL OF KNOWLEDGE MANAGEMENT, VOL. 16 NO. 2, pp. 183-203.

Scherer, E. 2000. "The knowledge network: knowledge generation during implementation of application software packages", Journal of Enterprise Information Management, Vol. 13 No. 4, pp. 210-217.

Soo, C., Devinney, T., Midgley, D. and Deering, A. 2002. "Knowledge management: philosophy, processes and pitfalls", California Management Review, Vol. 44 No. 4, pp. 129-150.

Suli Zheng, Wei Zhang, Xiaobo Wu and Jian Du. 2011. "Knowledge-based dynamic capabilities and innovation in networked environments", JOURNAL OF KNOWLEDGE MANAGEMENT, VOL. 15 NO. 6, pp. 1035-1051.

Tidd J. 2006. From Knowledge Management to Strategic Competence: Measuring Technological, Market And Organisational Innovation, World Scientific Publishing Company, London.

Trott P. 2009. Innovation management and New Product Development, Pearson Education Limited, Essex.

Verma, Rajeev and Jayasimha, K.R. 2014. "Service delivery innovation architecture: An empirical study of antecedents and outcomes". IIMB Management Review, 26, 105-121.

Vijande. Leticia Santos, María J. Sanzo-Pérez, Juan A. Trespalacios Gutiérrez, Nuria García Rodríguez. 2012. "Marketing Capabilities Development in Small and Medium Enterprises: Implications for Performance", Journal of CENTRUM Cathedra, Volume 5, Issue 1, pp. 24-42.

Zack, M., Mckeen, J. and Singh, S. 2009. "Knowledge management and organizational performance: an exploratory analysis', Journal of Knowledge Management, Vol. 13 No. 6, pp. 392-409. 